\title{
The Impact of Culture, Identity and Intergenerational Connections on Indigenous Youth Mental Health: Qualitative Findings from a Longitudinal Digital Health Community Trial
}

\section{Susannah Walker}

University of Regina https://orcid.org/0000-0002-9466-382X

\section{Prasanna Kannan}

University of Regina

Jasmin Bhawra

University of Saskatchewan

Heather Foulds

University of Saskatchewan College of Kinesiology

Tarun Reddy Katapally ( $\nabla$ tarun.katapally@usask.ca )

University of Regina https://orcid.org/0000-0001-5765-1435

\section{Research}

Keywords: Indigenous youth, culture, citizen science, mental health, digital health, qualitative research, land-based programs, Indigenous health

Posted Date: October 11th, 2021

DOl: https://doi.org/10.21203/rs.3.rs-956256/v1

License: (c) (i) This work is licensed under a Creative Commons Attribution 4.0 International License.

Read Full License 
Title: The impact of culture, identity and intergenerational connections on Indigenous youth mental health: Qualitative findings from a longitudinal digital health community trial

Authors: Susannah Walker ${ }^{1}$, Prasanna Kannan ${ }^{2}$, Jasmin Bhawra ${ }^{3}$, Heather Foulds ${ }^{4}$, Tarun Reddy Katapally

Corresponding Author: Tarun Reddy Katapally

Johnson Shoyama Graduate School of Public Policy, University of Regina

3737 Wascana Parkway, Regina, SK, S4S 0A2

Phone: +13065854544

Email: Tarun.katapally@uregina.ca

\footnotetext{
${ }^{1}$ Johnson-Shoyama Graduate School of Public Policy, University of Regina, Regina, Saskatchewan, Canada

2 Johnson-Shoyama Graduate School of Public Policy, University of Regina, Regina, Saskatchewan, Canada

${ }^{3}$ Johnson Shoyama Graduate School of Public Policy, University of Saskatchewan, Saskatoon, Saskatchewan, Canada

${ }^{4}$ College of Kinesiology, University of Saskatchewan, Saskatoon, Saskatchewan, Canada
} 


\begin{abstract}
Background: Indigenous youth in settler nations are susceptible to poor mental health due to complex inter-generational systemic inequities. The purpose of this study is to assess the impact of a culturally-responsive, land-based, active living initiative on the mental health of Indigenous youth.

Methods: This study is part of Smart Indigenous Youth (SIY), a mixed-methods 5-year longitudinal digital citizen science initiative. SIY embeds culturally-responsive, landbased active living programs into the curricula of high schools in rural Indigenous communities in the western Canadian province of Saskatchewan. In year-1 (Winter 2019), 76 Indigenous youth citizen scientists (13-18 years) from 2 schools participated in the study. At the beginning of the term, each school initiated separate 4-month landbased active living programs specific to their culture, community, geography, and language (Cree and Saulteaux). Before and after the term, focus groups were conducted with the 2 Youth Citizen Scientist Councils, which includes students from both participating schools. This study includes data from focus groups of one participating school, with 11 youth citizen scientists ( 5 boys, 6 girls). Focus group data were transcribed and analyzed by two independent reviewers using Nvivo to identify themes and subthemes. Both reviewers discussed their thematic analysis to come to a consensus about final findings.
\end{abstract}

Results: Baseline focus group analyses revealed themes demonstrating the importance of Indigenous culture, identity, history, and language. Youth emphasized the impact of loss of language and culture, the importance of being a helper, and the necessity of intergenerational knowledge transfer. Follow-up focus group analyses indicated that cultural school programming led to students expressing positive mental health benefits, increased interest in ceremonies, increased participation in physical activity, and greater knowledge of culture, identity, and ceremonial protocol.

Conclusions: Land-based active living can play a critical role in improving Indigenous youth mental health. This study highlights the importance of linking active living with culture and the potential of leveraging citizen-owned ubiquitous tools in implementing interventions in rural communities. Digital citizen science shows promise for supporting Indigenous youth mental health initiatives.

Keywords: Indigenous youth; culture; citizen science, mental health; digital health, qualitative research; land-based programs, Indigenous health 


\section{Background}

In Canada, Indigenous Peoples consist of three groups: First Nations, Inuit, and Métis. The discriminatory categorization of Indigenous Peoples in Canada is a complex subject, which could be perused in Smylie and Allan's report, "First Peoples, Second Class Treatment" (Allan \& Smylie, 2015). Many First Nations people in Canada live on reserves, which are pieces of land allotted to First Nation bands in Canada under the Indian Act, where First Nation band members have the right to live, and band administrative and political structures are located. First Nations do not have title to reserve lands, which are held in trust for bands by the British Crown (Hanson, 2009).

Historical and intergenerational trauma have contributed to greater health issues among many Indigenous communities, with Indigenous youth in Canada having suicide rates two to three times higher than the national average (Health Canada, 2013). Some studies have reported suicide rates as high as five to six times the national average (Centre for Suicide Prevention, 2013). Connected to these issues of mental health are culture loss, which includes both tangible losses of language, tradition and customs, and historical trauma. This complex phenomenon is in turn connected to "depression, self-destructive behaviour, suicidal ideation and attempts, anxiety, low self-esteem, and self-medicating to try and hide painful emotions" (Evans and Davis, 2018, p. 1). Other issues that disproportionately affect Indigenous youth include gang involvement, lack of educational attainment, and poor health, including teen pregnancy, sexually transmitted infections (Totten, 2009) and lower rates of quality physical health (Gates et al., 2016).

Many reports have been commissioned to confront and offer solutions to these problems. The Federation of Sovereign Indigenous Nations, which represents 74 First Nation communities in Saskatchewan, released their report on youth suicide in 2018, noting that Indigenous people have been overrepresented in suicide completion since 1978 (FSIN, 2018, p. 13) and identifying the need for comprehensive cultural teachings (FSIN, 2018, p. 22). After a tragic shooting in the small Dene community of La Loche, Saskatchewan, Canada, youth were asked what they needed to change in their community, and a key need was the renewal of culture (Kruchak, 2016). These reports, along with more comprehensive national reports such as the Royal Commission on Aboriginal Peoples report in 1996, the Truth and Reconciliation Commission report, and health reports on the impact of trauma and historical oppression (Aguiar and Halseth, 2015), highlight that the key recommendation for prevention of suicide and amelioration of mental health issues is connecting youth with their culture.

Recent research from Snowshoe et al (2017) delineated the impact of cultural knowledge on improving mental health for Indigenous youth and the protective effect of culture. For instance, Indigenous youth who report greater cultural connectedness tend to have better health outcomes, and culturally-based interventions have shown promise for Indigenous youth in Canada (Ritchie et al, 2014), Australia (Dockery, 2020) and the United States (Evans and Davis, 2018). Moreover, the offering of traditional school programming in language and culture under the leadership of school personnel who speak and understand Indigenous languages can significantly increase engagement of Indigenous youth (Davison and Hawe, 2012, p. 69). 
School-based activity programs including physical activity, sport, or recreational activities are beneficial for the holistic development of Indigenous youth. Such programs not only provide benefits in terms of mental health, but also improve perceived spiritual health. For example, evidence indicates that cultural activities such as powwows, prayers and teachings from Elders significantly enhance youth spiritual wellbeing. Activities such as hunting and fishing have potential to strengthen youth connections to the land and support the development of relationships in Indigenous communities, including family and community member support (Coppola and McHugh, 2018).

Sports may be considered as one of the "most salient mediums for recapturing spirits" among Indigenous people in Canada (Coppola \& McHugh, 2018, p. 14). Particularly, participating in traditional games enhances the sport experiences of Indigenous youth by promoting cultural pride, interaction with Elders, connection with land, and development of positive personal characteristics (Dubnewick et al, 2018). Such engagement of Indigenous youth in school activity programs is dependent on participation of Indigenous educators, support on campus, and in the community, including Elders and counselors. (Clark and Drolet, 2014).

Evidence from Australia indicates numerous health benefits of youth participation in cultural activities (Dockery, 2020). Additionally, when these interventions happen earlier in life, children can display more positive developmental outcomes (Dockery, 2020), which provides a basis for ensuring greater access to cultural programming in schools to equalize access. Considering the challenging outcomes for Indigenous youth and the benefits of culture, the Smart Indigenous Youth (SIY) initiative was developed. SIY embeds culturally-responsive, land-based, active living programs into Indigenous school curricula to improve youth mental health and address gaps in research on culturally appropriate, land-based and innovative technological solutions. As part of the larger SIY initiative, this study aimed to identify the association between culture and the mental health of Indigenous youth who participated in the land-based active program that was tailored to their culture, language, and history.

\section{Methods}

\subsection{Smart Indigenous Youth}

SIY is a mixed-methods 5-year longitudinal citizen science initiative that embeds culturally-responsive, land-based active living programs into school curricula. SIY is part of the Smart Platform, a citizen science and mobile health initiative for ethical engagement, integrated knowledge translation, and policy and real-time interventions (Katapally, 2019). The Smart Platform uses digital citizen science to co-create knowledge with all participants (Katapally, 2020).

SIY uses a Two-Eyed Seeing approach to work with, and alongside Indigenous communities. Two-Eyed Seeing, conceptualized by Mi'kmaw Elder Albert Marshall, notes that "there are diverse understandings of the world and that by acknowledging and respecting a diversity of perspectives (without perpetuating the dominance of one over another) we can build an understanding of health that lends itself to dealing with some of the most pressing health issues facing Indigenous peoples and communities" (Martin, 2012, p. 24). SIY integrates Traditional Knowledge and digital citizen science 
through community-based participatory research approaches (Katapally 2019; Katapally, 2020) to address health issues facing Indigenous peoples and communities" (Martin, 2012, p. 24). This approach involves community members at each step of the research process, seeking to build equity into academic projects (Coppola, Holt, \& McHugh, 2020, p. 321). Collaboration is a critical component, as well as conducting research that has tangible and relevant benefits to Indigenous communities.

Community-based participatory research action seeks to give to communities instead of simply taking data and information (Coppola, Holt, \& McHugh, p. 321).

Extensive preparation was done prior to beginning the SIY project, including seeking guidance and input from Elders and knowledge keepers, building relationships with school personnel, and following respectful cultural protocol such as the gifting of tobacco to Elders and knowledge keepers. Before the implementation of SIY, our team built strong partnerships with the communities based on equity, respect, and ownership. This partnership exemplifies not only study co-conceptualization and co-creation of knowledge, but also Indigenous ownership of data and integrated knowledge translation. School personnel who became stakeholders in the project had multiple points of input into the project's formation and roll-out in the schools through meetings with SIY personnel, and were able to read, offer revisions and approve written articles about the SIY Project as the project progressed. All youth contributing to SIY are citizen scientists, who engage with the research team at the beginning, during, and end of each school term. This engagement is governed by the Youth Citizen Scientist Advisory Council consisting of students from the participating schools. Additionally, the SIY Project has a results-driven approach, which aims to share data, resources, and knowledge with the schools to leverage results for changes in curricula to benefit Indigenous students.

In year-1 (Winter school term in 2019), 76 Indigenous youth citizen scientists (1318 years) from two schools participated in the study. At the beginning of the term, each school initiated separate four-month land-based active living programs that were specific to their culture, community, geography, and language (Cree and Saulteaux). Before and after the term, focus groups were conducted with two separate Youth Citizen Scientist Councils, one from each participating school. The Youth Citizen Scientist (YCS) Councils consist of youth who participated in the larger project and agreed to participate in the focus groups. Moreover, during the 4-month intervention period from January to May 2019, YCSs engaged with researchers in real-time using their own smartphones via a custom-built application to provide their perceptions of the initiative (Katapally, 2020). This longitudinal qualitative study includes data from the preand post-intervention focus groups of one of the participating schools. These focus groups were conducted with 11 youth who formed the Youth Citizen Scientist Advisory Council ( 5 boys, 6 girls).

\subsection{Procedures}

To ensure respectful data collection, this study followed relevant articles outlined in Chapter 9 of the Tri-Council Policy Statement 2, the Canadian Institutes of Health Research (CIHR) guidelines for working with Indigenous Peoples, and the principles of Ownership, Control, Access, and Possession (OCAP®) from the First Nations 
Information Governance Centre (First Nations Information Governance Committee, 2007).

The Tri-Council Policy Statement on ethical research with Indigenous communities outlines a number of important articles to conduct appropriate and respectful research that are applicable to the SIY Project, including Article 9.12: Collaborative Research, Article 9.13: Mutual Benefits in Research, Article 9.15: Recognition of the Role of Elders and Other Knowledge Holders, and Article 9.16: Privacy and Confidentiality (TCPS, 2018). SIY also follows CIHR guidelines for creating cultural safety, which is "a participant-centred approach that encourages self-reflexivity among health researchers and practitioners ... [and] requires building trust with Indigenous Peoples and communities in the conduct of research" (CIHR, 2020). To respect $O C A P \AA$, ownership of data by the Indigenous communities is a key part of the SIY Project (First Nations Information Governance Committee, 2007).

\subsection{Culturally-responsive, land-based intervention}

The land-based intervention component of the program was created and administered by school personnel in partnership with Elders, knowledge keepers, and our research team. The focus of the intervention was holistic wellness, including physical, mental, emotional, and spiritual health.

The school, based in Saskatchewan, will be referred to as School 1 to preserve its anonymity. School 1 chose to implement a combination of sports and cultural activities, including sweats, pipe ceremonies, Elder and knowledge keepers guest talks, art activities including moosehair embroidery and quill work, feasts, dancing, ice fishing, medicine walks (walks in nature with Elders and knowledge keepers to collect sacred medicines such as sage and sweetgrass) and plant identification using Cree language. The activities also included community events such as Flower Day (a day to honour ancestors), and a lodge with ceremonies such as the Rain Dance and Sun Dance. Activities were offered approximately three times per month over the winter term. Students were encouraged to participate in all activities but attendance was not mandatory. Educators, administrators, Elders, artists, family members and cultural teachers participated in the programming. Youth who participated in the land-based activities were asked to take pictures via the custom-built smartphone app. Questions were pushed in real time to allow youth to capture photos and audio during the landbased activities (Figures 1 and 2). These ecological momentary assessments enabled the youth citizen scientists to provide critical information about their perception and engagement with the intervention. 


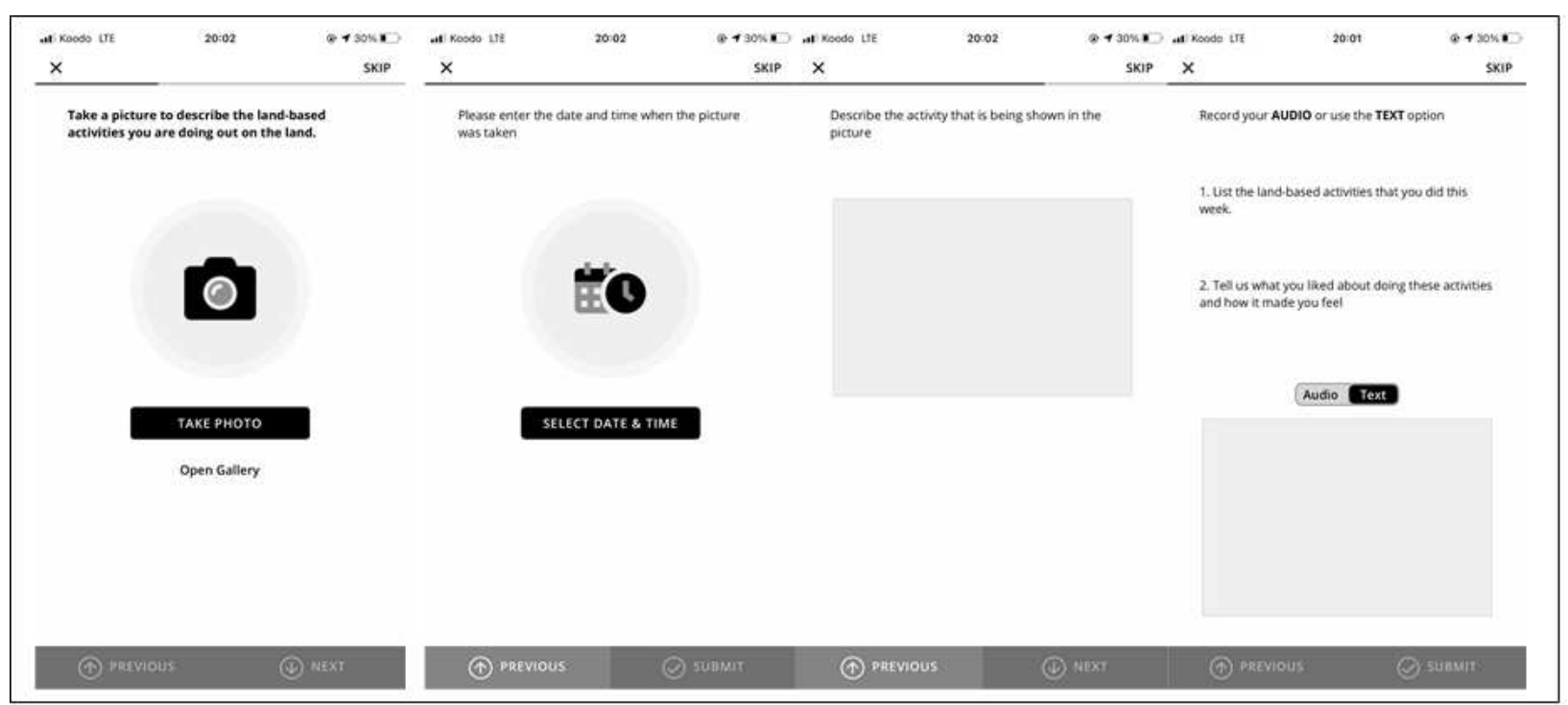

Fig. 1. Citizen scientist engagement via the smartphone app.

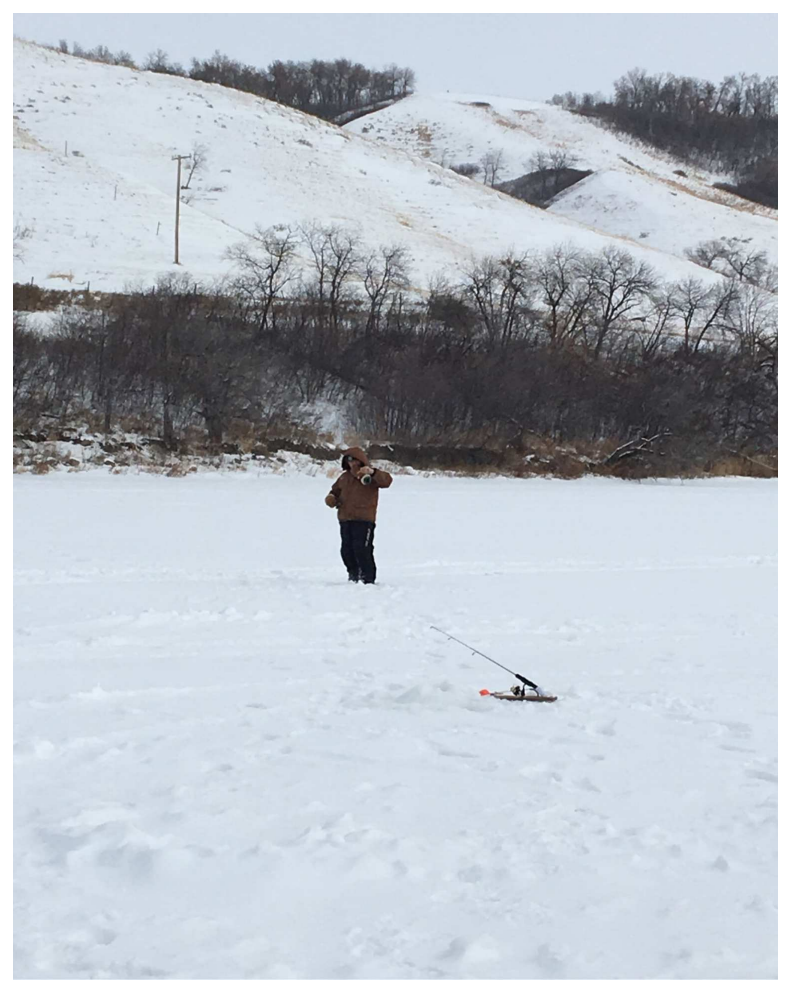

Fig. 2. Youth participating in land-based activity.

\subsection{Qualitative data collection}

The focus groups with the Youth Citizen Scientist Advisory Council (11 students aged 13-18 years) were conducted in two talking circles to respect Indigenous ways of knowing: one circle for the boys $(n=5)$, and another circle for the girls $(n=6)$. The separate circles were formed based on the feedback from the school administrators, 
educators, Elders, and the students themselves. The design also ensured that the same students participated in pre- and post-intervention focus groups. Focus groups were facilitated by two Indigenous graduate students and included a small incentive as a gift for the student participants. Incentives included toques, frisbees, and jump ropes to encourage physical activity. Indigenous facilitators began the circle with a smudge and a prayer, and passed around a small stone for participants to hold as they spoke. The smudge was left burning in the centre of the circle for participants' comfort and in respect to the emotional topics of identity and perception of mental health. One facilitator asked the questions and the other took notes for the students to see on a large whiteboard. The circle was closed by shaking hands.

Pre- and post-intervention semi-structured focus group templates (Appendix 1) were developed collaboratively with the school to capture the impact of the culturallyresponsive, land-based, active living program on youth perception of mental health. Based on the type of land-based activities that the school implemented, the postintervention focus group template was tailored to capture changes in youth behaviours and outcomes. Mental health supports were available through the school in the event that students experienced any emotional difficulties from their participation in the focus groups. Before any data were collected "ethics approval was obtained from the Research Ethics Boards of Universities of Regina and Saskatchewan through a synchronized review protocol (REB \# 2017-29)" (Katapally, 2020, p. 3). More importantly, every youth citizen scientist provided informed consent before both focus groups, where they had the opportunity to ask questions about data privacy, security, and sovereignty. They were advised that their participation was completely voluntary. After taking permission from the youth, focus groups were recorded and transcribed by the SIY research team. The research team was in constant communication with the school principal and educators to prepare for any potential barriers.

\subsection{Data Analysis}

Focus groups were audio-recorded, and data were anonymized during transcription into Word documents. The Word documents were then uploaded into NVivo 12 to thematically code and analyze data. Two researchers completed data analysis using the word frequency query tool in NVivo. The most common words and phrases were used to create a number of 'nodes' or categories. The researchers then reviewed the nodes for commonalities and combined them into four overarching nodes, i.e., themes. These four 'parent' nodes were then reviewed and the researchers created 'child nodes' or sub-themes within each theme. By reading and rereading the data, the researchers selected the most relevant and impactful quotations from focus group participants to illustrate each sub-theme. A final review was completed by both researchers to look for further patterns or areas of overlap among the themes before selecting the final themes and sub-themes. Each researcher completed the thematic coding independently, both using NVivo and manually, and then compared their findings before coming to a consensus. A third researcher reviewed the transcripts, thematic coding, and themes and sub-themes for accuracy and coherence before validating the consensus of the first two researchers. This was a collaborative process between researchers to find greater meaning, objectivity, and understanding from the transcript data. 


\section{Results}

The four main themes that emerged from focus group discussions with youth citizen scientists were: Indigenous culture, identity, mental health and physical activity, with youth emphasizing the impact of the loss of language and culture, the importance of being helpers, and the necessity of cultural connectedness across generations. Intergenerational transmission of knowledge, both from Elders and to younger generations, was also noted.

In particular, post-intervention focus group analyses showed that through participation in the land-based school programing, students expressed increased interest in ceremonies, knowledge of culture, identity, and ceremonial protocol. There were a number of overlapping themes across boys and girls, including the impact of loss of culture and tradition, importance of intergenerational transmission of knowledge, value of peer support, need for sports and physical activity, and the positive impact of the culturally-responsive, land-based, active living school program.

\subsection{Themes and sub-themes}

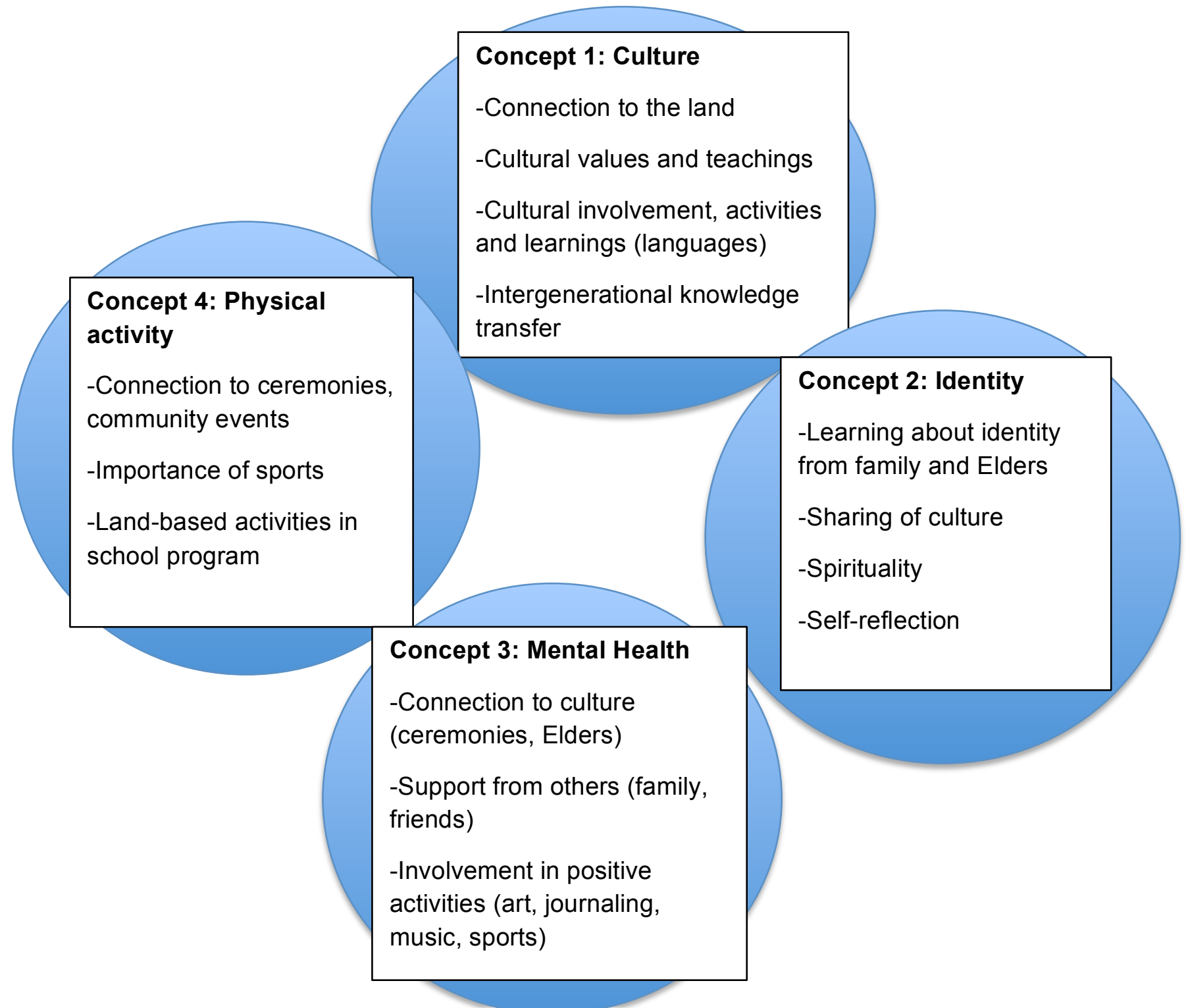


Fig. 3. Themes and sub-themes

\section{Concept 1: Culture}

At baseline (i.e., pre-intervention), youth citizen scientists were asked about the importance of culture and how they defined culture. In the follow-up focus groups, we discussed if and how the land-based programming influenced their understanding of culture. The overall concept of culture elicited a number of sub-themes, including connection to the land, cultural involvement, cultural values and teachings, cultural activities and learnings (languages), and intergenerational knowledge transfer.

Connection to the land: Female students identified female teachings (moontime or menstrual cycle teachings), the connection to Mother Earth, and the value of walking around on the land as an enjoyable activity. Respect and gratitude for the land were also mentioned by students in the follow-up focus group as a change from participating in the land-based program.

Cultural involvement, activities, and learnings: Both male and female students mentioned their involvement in ceremonies, such as sweats, round dances, powwows, shaking tent, rain dances, sundances, tipi teachings, and dancing powwow. Students also discussed being involved with cultural activities through school, including traditional sports, daily smudging, beading, ribbon skirt making, sage picking and school-organized sweats. The boys mentioned specifically being culturally involved by being a helper, both at ceremonies and with Elders in the community. Multiple male participants expressed that they stayed involved in their culture by "just helping out at ceremonies and stuff. Giveaways, feasts and stuff. Round dances" (Citizen Scientist 2, p. 4) and by "helping the Elders get the trees and all that" (Citizen Scientist 3, p. 4). Others shared that they enjoyed "helping out Elders. Helping out Elders with cultural stuff ... helping out at ceremonies" (Citizen Scientist 2, p. 4-5) and in the community by "helping Elders cut trees for their wood stoves" (Citizen Scientist 4, p. 5). The role of a helper for ceremonies is traditionally a male role and it was evident that this resonated with the boys' group.

Cultural values and teachings: Helping Elders, listening to stories, respecting Mother Earth, and knowing the protocol for ceremonies were all mentioned as cultural values and teachings. Passing on knowledge was also a key aspect. Having a positive mind when participating in ceremony was identified as important, as was knowing the language.

Intergenerational knowledge transfer. Students identified the loss of culture and language due to residential schools as something that was concerning to them, and the importance both of teaching the younger generations about culture and traditions, and taking the time to learn from Elders. One female student shared that her culture was important to her "because, well, usually like back then, the kids would be born into that kind of lifestyle and like after all residential schools and all that stuff happened, Natives kind of lost their language and their traditions. And I find it like really important to keep it, keep learning about it and keep trying to learn your language and stuff like that, because if not, then our language and traditions would no longer be, I guess" (Citizen Scientist 5, p. 2). 


\section{Changes between pre and post intervention}

Respect and gratitude for the land were mentioned by students in the girls' follow-up focus group as a change from participating in the land-based program. Citizen Scientist 3 noted that for her, culture means "just how to respect the land and what we're given and to be very grateful about the life that we have" (Citizen Scientist 3, p. 2). Citizen Scientist 4 also noted that the land-based programs "made me think that the like, I started not to litter that much because I think about it and I think about how the world is so important to us. And I think about how this world is going to go in trash pretty soon trying to like - just want people to take care of it more. Whenever I - like my friends throw something on the garbage I'm like pick it up! and put it in my bag because I'm going to put it in the garbage later. And that's what yeah - I just care about what's happening now and we should take care of it and we should respect it" (Citizen Scientist 4, p. 7).

Keeping culture going was identified as very important in the female follow-up focus group. One participant noted that she "learned that our culture plays a big role in our future life and in our present life" (Citizen Scientist 3, p. 2). Generational connections were identified by participants as well; one participant remarked that "most of those activities are going to last a long time, a lot of generations because people like it and we should pass it on too to keep it going" (Citizen Scientist 4, p. 2). Another expressed that she was "really thankful that it's actually getting passed down to us because it means a lot to like know what our people did in the past and that it's still present to this day" (Citizen Scientist 6, p. 3). Others expressed their own sense of responsibility for cultural knowledge by saying "we just gotta keep it going, make it known and it's very important to have it" (Citizen Scientist 7, p. 3) and "I want to pass it on to other people when they're younger and I want to teach it properly" (Citizen Scientist 4, p. 4).

Additionally, a key change identified in the female follow-up focus group was having acquired more cultural knowledge from the land-based program. One participant said, "I feel like it gives it more meaning and I know what's going on. And I know how to react to different things" (Citizen Scientist 3, p. 4). Another participant expressed that culture "is important to me because from not knowing about the, um, activities made it more important because I know how they work and how to like respect them and respect other people around me" (Citizen Scientist 5, p. 4). Lastly, another participant expressed that culture "is important to me because it actually tells me who I am and who I want to be and just gives me more knowledge to pass down. Uh, it also helps with just yourself, what you believe in and like just how you see yourself and other people and the world" (Citizen Scientist 7, p. 4). These changes are important because they could help reduce barriers for Indigenous youth to participate in cultural activities.

\section{Concept 2: Identity}

In the focus groups, students were asked about how they learned about their identity. A number of sub-themes emerged: learning about identity from family and Elders, sharing of culture, spirituality, and self-reflection. 
Learning about identity from family and Elders: Participants mentioned learning their identity through family members, especially parents and grandparents, through language and through school. One participant expressed that she was taught that her "identity was in [her] community, at school and [from her] parents and grandparents, pretty much the people that surround me" (Citizen Scientist 4, p. 3). The Cree language program at the school was mentioned as a key aspect of learning identity, especially since one participant shared that her family didn't speak the language at home: "I learnt it in kindergarten. [Laughter] with all our - with my teachers. Well she is still here today. When I was in kindergarten, my mom really never talked about it or my parents, because they don't really do that stuff. So, yeah mostly at school" (Citizen Scientist $3, p$. $3)$.

Sharing of culture: Sharing of culture with non-Indigenous people was identified as a benefit of the school program. Sharing culture with younger people, including siblings, was identified as important.

Spirituality: Identity was connected to spirituality through the participation in ceremony such as sundance, raindance, speaking Cree language, and doing sweats. Participants also talked about learning cultural identities through elders and teachers.

Self-reflection: Participants discussed identity as something that shows who they are. Identity comes from knowing who they are and where they come from and so on which is transformed from parents and grandparents. Identity is also perceived as a way people think, act and respond to people in the community.

\section{Changes between pre and post intervention}

When asked about changes in their identity from participating in the land-based program, the girls' follow-up focus group identified two important changes around the theme of identity: feelings of goodness and changed feelings about self. One participant described how she viewed the change: "I do feel a change like I feel that my spirit is fed ... like with goodness" (Citizen Scientist 3, p. 5). Another participant expressed that after participating in cultural activities that "I feel good about myself because I always feel good after" (Citizen Scientist 4, p. 5). Another key change that was noted by other participants was changed feelings about self. One participant said that "it kind of changed how I feel about myself" (Citizen Scientist 5, p. 5). Another said that her worldview had changed, expressing that "there will be a change in the world and how you see it, and then how you see yourself" (Citizen Scientist 6, p. 6). These findings highlight the connection between positive self-concept and mental health.

\section{Concept 3: Mental health}

Students were asked how they defined the term 'mental health' and they shared that mental health meant positive thinking and surrounding themselves with good people. One participant defined mental health as: "What mental health means to me is to take care of your mind. [Laughter] Just like positive thinking into your mind, not negative thinking. So, listening to music, listening to positive powwow music, it will give you good thoughts" (Citizen Scientist 3, p. 6). The sub-themes that emerged were connection to culture, support from others, and involvement in positive activities. 
Connection to culture: Students discussed the contribution of ceremonies to positive mental health, including the necessity of participating in ceremony with a positive mind, and the ability of ceremonies such as sweats to transform bad feelings. The boys in particular mentioned helping Elders in the community and at ceremony as connected to mental health.

Support from others: Students mentioned relying on others for support with their mental health, including talking about feelings and issues with family members and friends.

Involvement in positive activities: Students mentioned journaling, drawing, cultural activities such as beading, and playing sports to deal with thoughts and emotions.

\section{Changes between pre and post intervention}

In the girls' follow-up focus group, students reported a number of changes in perception of mental health as a result of participating in the land-based program, including feeling refreshed/cleansed, feeling a connection to the land, reduction in stress, being grounded in the present, and thinking more positively. One participant noted the positive impact of participating in ceremonies: "If I do go to sweats, I do feel like more refreshed. And - or like a powwow or a feast, or anything like that, I just feel like refreshed and like, I don't know. Just feels like - like cleansed, especially after a sweat" (Citizen Scientist 3, p. 7). Another noted the positive impact of cultural activities on reducing overthinking and stress: "... because before when I never used to, like, go to any of these things l'd just chill out and like just think about things, and sometimes it gets overwhelming and like, stresses me out and things like that, but when I like go to like, these cultural things, it just like takes all that off my mind, and just like focuses on what's happening at the moment" (Citizen Scientist 5, p. 8). Another participant noted how her thinking had changed for the better after taking part in the land-based program, "[It] changed my perception of mental health a lot actually. Like, things weren't really as good as they were now, and now that like I've been going to them I think more positively and I'm like really glad that our people do have these things and that we get to learn about them" (Citizen Scientist 6, p. 8). Lastly, one participant spoke of finding more direction for herself as, "the programs I went to changed me and this did too, because basically I feel more just interested and humble and more mature with what I want to do. And I feel like that if I keep on doing it then maybe I would get inspiration" (Citizen Scientist 7, p. 8).

\section{Concept 4: Physical activity}

When asked about physical activity, youth discussed the connection between ceremonies and community events, the importance of sports, and the land-based activities in the school program.

Connection to ceremonies, community events: When asked how people stayed physically active in the community, youth mentioned ceremonies such as sundances and sweats.

Importance of sports: Students mentioned how much they enjoyed the sports offered at school and the activities associated with sports teams, along with physical education 
class and gym nights offered at the school. Community sports events and community sports nights were popular.

Land-based activities in school program: Students discussed how much they liked landbased activities such as medicine picking, ceremonies such as sweats, and other cultural activities such as beading and skirt-making.

\section{Changes between pre and post intervention}

When asked about changes occurring from participating in the land-based program, the girls' follow-up focus group identified a number of changes around their feelings about school. Two participants expressed their interest in learning new things through the land-based program and how these programs made them want to be at school more often: "It does make me want to go to school more. Because obviously it's an opportunity to learn something new instead of putting the same old stuff in school. [laughter] It's actually something that's like fun and interesting and has a real - well not real, but like a cool story behind it and why" (Citizen Scientist 3, p. 9). The other participant shared her excitement at knowing there were cultural activities planned for school: "it made me like want to come to school more and it's like - really awesome I guess, like, just like, [teacher] or someone coming saying, oh there's going to be a sweat or there's a pipe ceremony - it just like - I'm like yes! [laughter] Yay! And yeah, it's just good" (Citizen Scientist 6, p. 10). Another participant noted that these types of programs increase the profile of the school, saying that "I think these programs make our school look better ... it feels good" (Citizen Scientist 4, p. 9). Another participant expressed her enjoyment of learning about culture through school: "it makes me feel good because when you're just at home or something, not at school, just nothing to learn about but when you come to school and there's opportunities to learn something new about your culture it's kind of - pretty, pretty dope" (Citizen Scientist 5, p. 10). Lastly, connected to the previous theme of intergenerational knowledge transfer, one participant expressed pride in sharing cultural knowledge with school visitors: "It's like good because it just brings like more information to our school and us sharing who we are to people who come to our school and what they teach us, like say if they come to our school and teach us something or tell us something and we experience it, it's not only them teaching us, it's us teaching them" (Citizen Scientist 7, p. 10).

\section{Discussion}

This longitudinal qualitative study aimed to identify the association between culture and the mental health perception of Indigenous youth who participated in the land-based active living program that was tailored to their culture, language, and history. The overarching findings showed strong connections between culturally-sensitive, landbased learning and perception of positive mental health among Indigenous youth.

These findings contribute to our understanding of the importance of cultural identity for Indigenous youth to protect them against negative mental health outcomes and provide them with resilience. The findings align with existing evidence that shows that Indigenous youth with connections to their cultural identity reported greater degrees of resilience (Snowshoe et al., 2017, p. 70). Given the positive impact of cultural 
activities on students' perception of mental health, it is important for schools to provide Indigenous students with opportunities to participate in ceremonies. For example, providing sweats either on-site or partnering with community Elders to provide opportunities for students to participate would be a culturally-appropriate way to meet this need.

The results also showed the importance and need for land-based activities in potentially improving Indigenous youth holistic health i.e., the concept of health as portrayed by Indigenous youth citizen scientists shows the impact of land-based programming on not just physical health, but also mental, emotional and spiritual health. This concept of health aligns with Indigenous ways of knowing, and approach to wellbeing in Indigenous teachings, with the mental, emotional, physical and spiritual needing to be in balance for optimal health (Absolon, 2010; Baikie, 2010; Gray, Coates \& Bird, 2008; Loiselle and McKenzie, 2006).

As youth emphasized their interest in the activities that took them out of the classroom to connect with the land and their culture, it is important for schools to consider how they can adapt their curricula to incorporate land-based, active living - an approach that could have an impact on youth irrespective of their identity. Some gender-based differences emerged as boys expressed greater interest in gathering trees to assist Elders in building ceremonial structures, being on the land, helping Elders and being helpers at other community events. Providing opportunities for boys to participate in culture in these roles could be meaningful in facilitating a sense of value and wellbeing.

The findings show that land-based activities are of high interest to Indigenous youth and could be used as a natural way to build cultural knowledge and pique youth engagement. Land-based activities and curricula are increasingly popular for connecting Indigenous youth with their culture and identity (Walsh, Danto, \& Sommerfeld, 2020). However, in our study, we clearly depicted that land-based, active living programing can have a particularly positive impact on perception of Indigenous youth mental health, while enhancing cultural competence, identity, and active living i.e., these concepts are potentially inherently connected together to enhance holistic health. Another avenue of possibility is the connection between our results and shaping Indigenous youth attitudes towards mental health services. If mental health services have holistic, cultural, and land-based components to their programming, Indigenous youth may be more inclined to partake, which could have positive implications for improved overall mental health.

When considering the results, schools emerge as natural sites for cultural and mental health promotion for Indigenous youth. Building cultural programs with trusted teachers and knowledge keepers as a part of school programming for Indigenous youth would be a beneficial addition to on-reserve school curricula, as well as off-reserve schools with high populations of Indigenous youth. Cultural programs could be housed or offered as a part of comprehensive mental health services for students. Youth demonstrated high engagement and interest in cultural activities provided by the school. Some youth shared how they had learned about their Indigenous identity from school activities and teachers. Schools with Indigenous populations and on-reserve schools have a role in increasing cultural knowledge for Indigenous youth. School attendance 
rates could also be positively impacted. Dockery (2020) notes the importance of involving schools in cultural resurgence for Indigenous populations, noting there is "a need for changes in social attitudes and institutional practices to support and celebrate the maintenance of traditional Indigenous cultures" (p. 88).

Dockery (2020) also emphasizes that Indigenous "identification with those cultures, particularly within the education system, and the reversal of policies that are predictably contributing to the disappearance of cultural practices, knowledge and languages" (p. 88) can potentially play a key role in Indigenous cultural resurgence - a factor that can positively impact Indigenous youth perception of mental health, as depicted in our findings. Wanting to learn more about teachings, about ceremony, and about language was expressed by a majority of youth. Youth also demonstrated understanding of the scale of loss and the urgency of learning traditional knowledge in order to protect it going forward. Schools providing more opportunities for students to participate in culturally-based programming would help fill this interest expressed by students. Considering the past damages to Indigenous culture from oppression and abuse in the residential school system, providing avenues within the schools to remedy this, along with familial and community efforts, would be of benefit to Indigenous youth.

At a policy level, it would be beneficial for school curricula to be modified to include cultural or land-based programs at all Indigenous schools, with programs for all ages of students. Current programs such as the Cree immersion program in Saskatoon (APTN, 2016) or land-based programs at Bert Fox Community School in Fort Qu'Appelle, Muskeg Lake Cree Nation, or the Buffalo River School, among others, could be used as models (Eneas, 2019). The importance of intergenerational connection was expressed by both girls and boys in this study, including connections between past and present, youth and Elders, and teaching the next generation. Programs that provide avenues for this knowledge transfer between Elders and youth will help to build cultural knowledge, and strengthen identity (Burns Ross, 2016). This would create stronger connections between youth and their community, in addition to reflecting traditional ways of passing on knowledge (Yang and Warburton, 2018). In essence, providing intergenerational programs could have a meaningful impact for youth, both in the school and community setting.

Apart from the imminent need for culturally-sensitive, land-based school programming, a key recommendation from our study is the necessity for systems of care to move to a prevention-oriented, upstream, long-term model with flexibility and innovative approaches. For instance, we operationalized digital citizen science using smartphones of Indigenous youth to engage with them in real-time - this approach has potential to respond to Indigenous youth needs in real-time, an innovation that is particularly useful in remote Indigenous communities (Katapally et al., 2018). This approach points towards more upstream interventions and fewer reactive systems of care when Indigenous youth are in serious danger. Nevertheless, for the success of digital innovations in Indigenous communities, it is critical to incorporate Two-Eyed Seeing, community-based participatory initiatives.

\section{Strengths and Limitations}


The strengths of the study are the study design, youth empowerment, mixed methods and culturally respectful approach, the innovative citizen science strategies using digital technology to engage youth, and the holistic health benefits from participating (Katapally, 2020). Youth were empowered as citizen scientists through the focus group talking circle approach, which allowed them space to voice their thoughts and reflect on their identity and cultural needs. The mixed methods approach was collaborative, culturally respectful, and used digital technology to collect rich data and engage with the youth. Longitudinal qualitative study design is a major strength of this complex study as it allows us to track and empirically capture the impact of culturallysensitive, land-based active living programming on Indigenous youth perception of mental health.

Limitations of the study included the sampling strategy, compliance and response rate, logistical and technological issues, as well as participants' burden. Sampling was not random as School 1 self-selected to participate in the SIY project. Students were invited by school personnel to participate in the focus groups, and in essence selfselected themselves as well. In terms of compliance and response rate, there were attendance concerns with some of the youth, which impacted the follow-up focus group for boys. Another limitation includes logistical issues, as having a quiet space in a busy $\mathrm{K}-12$ school to conduct the focus groups was challenging. Technological challenges included inconsistent WiFi access, which required creative solutions from the researchers such as convincing schools to provide uninterrupted WIFI access to participating citizen scientists before, during, and after school hours. Students without consistent Internet access at home may have been excluded from participating fully in the SIY project. Lastly, the self-reporting component of the SIY project increases the bias and burden on participants.

\section{Conclusions}

Culturally-sensitive, land-based, active living school programs have immense potential to benefit Indigenous students by increasing school attendance, and enabling equitable access to upstream mental health solutions. Due to historical trauma and losses through the residential schools and other assimilationist measures, not all Indigenous families have cultural knowledge or access to cultural teachers; therefore, providing these programs through schools creates an equalizing dynamic to cultural learnings that can be of great benefit to Indigenous youth. Indigenous communities know what is best when it comes to their youth and solutions for their youth need to be Indigenous-led and based in traditional value systems. Our study also offers a window into the future of upstream interventions in partnership with Indigenous communities, where Indigenous youth can be engaged in real-time via their digital devices, while participating in culturally-sensitive, land-based school programming that promotes culture, identity, and mental health.

\section{List of abbreviations}

SIY - Smart Indigenous Youth 
TRC - Truth and Reconciliation Commission

YCSs - Youth Citizen Scientists

\section{Declarations}

- Ethics approval and consent to participate: The study was conducted according to the guidelines of the Declaration of Helsinki, and approved by the Research Ethics Board of University of Regina and University of Saskatchewan ( $U$ of R File \# 2017-029 and U of S file:\# BEH 17-68 and date of approval is March 23, 2017). Informed consent was obtained from all participants involved in the study.

- Consent for publication: Not applicable.

- Availability of data and materials: The data presented in this study are available on request from the corresponding author.

- Competing interests: The authors declare no conflicts of interest.

- Funding: This study was funded by the Canadian Institutes of Health Research's Project Grant (\#153226).

- Authors' contributions:

- Affiliations:

SW - Johnson Shoyama Graduate School of Public Policy, University of Regina, Regina, Saskatchewan, Canada

PK - Johnson Shoyama Graduate School of Public Policy, University of Regina, Regina, Saskatchewan, Canada.

JB - Johnson Shoyama Graduate School of Public Policy, University of Saskatchewan, Saskatoon, Saskatchewan, Canada

HF - College of Kinesiology, University of Saskatchewan, Saskatoon, Saskatchewan, Canada

TRK - Johnson Shoyama Graduate School of Public Policy, University of Saskatchewan, Saskatoon, Saskatchewan Canada

- Contributions: Conceptualization, TRK; methodology, TRK, JB; software, SW, PK; validation, JB; formal analysis, SW, PK, JB; investigation, TRK; resources, TRK; data curation, SW,PK; data interpretation, TRK, HF, SW, JB, PK; writing—original draft preparation, SW .; writing—review and editing, JB, HF, TRK.; funding acquisition, TRK.

- Acknowledgements: The principal knowledge users of the Smart Indigenous Youth initiative are the school principals, the File Hills Qu'Appelle Tribal Council, and the Saskatchewan Ministries of Health, Education, and Sport. The Youth Citizen Scientist Advisory Council is involved in implementing Smart Indigenous Youth, and in shaping school policies and programs. We are grateful to the youth, educator, and administrator citizen scientists, and the staff and trainees of 
the Digital Epidemiology and Population Health Laboratory (DEPtH Lab) for their continuous support.

\section{References}

Absolon, K. (2010). Indigenous Wholistic Theory: A knowledge set for practice. First Peoples Child \& Family Review, 5(2), 74-87.

Aguiar, W., Halseth, R., National Collaborating Centre for Aboriginal Health, \& Canadian Electronic Library (Firm). (2015). Aboriginal peoples and historic trauma: The processes of intergenerational transmission. Prince George, B.C: National Collaborating Centre for Aboriginal Health.

Allan, B. \& Smylie, J. (2015). First Peoples, Second Class Treatment: The Role of Racism in the Health and Well-being of Indigenous Peoples in Canada. Wellesley Institute. https://www.wellesleyinstitute.com/wp-content/uploads/2015/02/Summary-FirstPeoples-Second-Class-Treatment-Final.pdf.

APTN. (2016, April). Saskatchewan elementary school offers Cree immersion to students APTN News

Baikie, G. (2009). Indigenous-centred social work: Theorizing a social work Way-of-Being. In Wícihitowin : Aboriginal social work in Canada, Hart, M., Sinclair, R., \& Bruyere, G. (2009), Eds. Black Point, N.S.: Fernwood Pub, p. 42-61.

Boksa, P., Joober, R., \& Kirmayer, L. J. (2015). Mental wellness in Canada's Aboriginal communities: striving toward reconciliation. Journal of Psychiatry \& Neuroscience: JPN, 40(6), 363.

Centre for Suicide Prevention. (n.d). Indigenous suicide prevention. Retrieved from https://www.suicideinfo.ca/resource/indigenous-suicide-prevention/

CIHR. (2020). Indigenous Peoples' Health. Defining Indigenous Health Research - CIHR (irsccihr.gc.ca)

Clark, N. \& Drolet, J. (2014). "Melq'ilwiye" Coming Together: Reflections on the journey towards Indigenous social work field education. Currents: Scholarship in the Human Services, 13(1).

Coppola, A. M., \& McHugh, T. L. F. (2018). Considering culturally relevant practices and knowledge-sharing when creating an activity-promoting community research agenda. Sport, Education and Society, 23(1), 14-27.

Coppola, A. M., Holt, N. L., \& McHugh, T. L. F. (2020). Supporting Indigenous youth activity programmes: a community-based participatory research approach. Qualitative Research in Sport, Exercise and Health, 12(3), 319-335.

Cornell, S. and Kalt, J.P. (1998). Sovereignty and nation-building: The development challenge in Indian country today. Harvard Project on American Indian Economic Development. Kennedy School of Government, Harvard University. Retrieved from https://hpaied.org/sites/default/files/publications/PRS98-25.pdf 
Davison, C.M \& Hawe, P. (2012). Students in Northern Canada: Perspectives. Journal of School Health, 82(2), 65-74.

Dockery, A. M. (2020). Inter-generational transmission of Indigenous culture and children's wellbeing: Evidence from Australia. International Journal of Intercultural Relations, 74, 80-93. https://doi.org/10.1016/j.ijintrel.2019.11.001

Dubnewick, M., Hopper, T., Spence, J. C., \& McHugh, T. L. F. (2018). "There's a cultural pride through our games": Enhancing the sport experiences of Indigenous youth in Canada through participation in traditional games. Journal of Sport and Social Issues, 42(4), 207-226.

Eneas, B. (2019, May). Land-based education in Sask. education system not just a trend: teachers | CBC News

Evans, W., \& Davis, B. (2018). Exploring the relationship between sense of coherence and historical trauma among American Indian Youth. American Indian and Alaska Native Mental Health Research, 25(3), 1-25. https://doi.org/10.5820/aian.2503.2018.1

Federation of Sovereign Indigenous Nations (FSIN). (2018). Saskatchewan First Nations suicide prevention strategy. Retrieved from https://www.fsin.com/wpcontent/uploads/2018/05/SFNSPS-FINAL-2018-May-24.pdf

Findlay, L. C. (2011). Physical activity among First Nations people off reserve, Métis and Inuit. Health Reports, 22(1), 47.

First Nations Information Governance Committee. (2007). OCAP: Ownership, control, access and possession. First Nations Information Governance Committee. Ottawa: National Aboriginal Health Organization. (Home | The First Nations Information Governance Centre (fnigc.ca)

Gates, M., Hanning, R., Gates, A., Stephen, J., Fehst, A., \& Tsuji, L. (2016). Physical activity and fitness of First Nations youth in a remote and isolated Northern Ontario community: A needs assessment. Journal of Community Health, 41(1), 46-56. https://doi.org/10.1007/s10900-015-0063-8

Gray, M., Coates, J., \& Bird, M. Y. (Eds.). (2008). Towards an understanding of Indigenous social work. Chapter 3 in Indigenous social work around the world: Towards culturally relevant education and practice. Ashgate Publishing, Ltd., p. 49-58.

Hanson, E. (2009). Reserves. https://indigenousfoundations.arts.ubc.ca/reserves/

Health Canada. (2013). National Aboriginal Youth Suicide Prevention Strategy (NAYSPS) Program Framework. Retrieved from https://www.canada.ca/content/dam/hcsc/migration/hc-sc/fniah-spnia/alt_formats/pdf/pubs/promotion/_suicide/strat-prev-youthjeunes-eng.pdf

Heroux, D. (2016, October). 'They're not just statistics. Our little girls are dying': FSIN vicechief. CBC. Retrieved from https://www.cbc.ca/news/canada/saskatoon/northern-sasksuicide-1.3830223 
Ironside, A. K., Ferguson, L. J., Katapally, T. R., \& Foulds, H. J. (2020). Cultural connectedness as a determinant of physical activity among Indigenous adults in Saskatchewan. Applied Physiology, Nutrition, and Metabolism, (ja).

Katapally, T. R. (2020). Smart Indigenous Youth: The Smart Platform Policy Solution for Systems Integration to Address Indigenous Youth Mental Health. JMIR Pediatrics and Parenting, 3(2), e21155.

Katapally, T. R., Bhawra, J., Leatherdale, S. T., Ferguson, L., Longo, J., Rainham, D., ... \& Osgood, N. (2018). The SMART study, a mobile health and citizen science methodological platform for active living surveillance, integrated knowledge translation, and policy interventions: Longitudinal Study. JMIR public health and surveillance, 4(1), e31.

Kruchak, M. (2016, January). La Loche hopes for better future after deadly shootings, struggles with youth suicides. CBC. Retrieved from https://www.cbc.ca/news/canada/saskatchewan/la-loche-monday-matthew-kruchakyouth-suicide-mental-health-resources-1.3418191

Loiselle, M. \& McKenzie, L. (2006). The wellness wheel: An Aboriginal contribution to social work. University of Waterloo, Renison College. Breaking Barriers and Creating Common Ground through a holistic approach: The Medicine Wheel.

Martin, D. H. (2012). Two-eyed seeing: a framework for understanding Indigenous and nonIndigenous approaches to Indigenous health research. Canadian Journal of Nursing Research Archive, 20-43.

O'Soup, C. (2017). Shhh...LISTEN!! We have something to say! Youth voices from the North. Office of the Saskatchewan Advocate for Children and Youth. Retrieved from https://www.saskadvocate.ca/sites/default/files/u11/listen_we_have_something_to_say nov_2017.pdf

Public Health Agency of Canada (2018). Key health inequalities in Canada: A national portrait. Retrieved from https://www.canada.ca/content/dam/phacaspc/documents/services/publications/science-research/key-health-inequalities-canadanational-portrait-executive-summary/hir-full-report-eng.pdf

Ritchie, S. D., Wabano, M. J., Russell, K., Enosse, L., \& Young, N. L. (2014). Promoting resilience and wellbeing through an outdoor intervention designed for Aboriginal adolescents. Rural and Remote Health, 14, 2523.

Ross, J. B. (2016). Indigenous intergenerational teachings: The transfer of culture, language, and knowledge in an intergenerational summer camp. American Indian Quarterly, 40(3), 216-250.

Shepherd, S. M., Delgado, R. H., Sherwood, J., \& Paradies, Y. (2018). The impact of indigenous cultural identity and cultural engagement on violent offending. BMC public health, 18(1), 1-7.

Simard, E. (2009). Culturally restorative child welfare practice-A special emphasis on cultural attachment theory. First Peoples Child \& Family Review: An Interdisciplinary Journal 
Honouring the Voices, Perspectives, and Knowledges of First Peoples through Research, Critical Analyses, Stories, Standpoints and Media Reviews, 4(2), 44-61.

Snowshoe, A., Crooks, C., Tremblay, V., \& Hinson, P. (2017). Cultural connectedness and its relation to mental wellness for First Nations youth. The Journal of Primary Prevention, 38(1), 67-86.

TCPS (2018). Chapter 9: Research Involving the First Nations, Inuit, and Metis Peoples of Canada. Tri-Council Policy Statement: Ethical Conduct for Research Involving Humans - TCPS 2 (2018) - Chapter 9: Research Involving the First Nations, Inuit and Métis Peoples of Canada (ethics.gc.ca)

Totten, M. (2009). Aboriginal youth and violent gang involvement in Canada: Quality prevention strategies. IPC Review, 3, 135-156

Truth \& Reconciliation Commission of Canada. (2015). Canada's residential schools: The final report of the Truth and Reconciliation Commission of Canada (Vol. 1). Montreal: McGill-Queen's Press.

Walsh, R., Danto, D., \& Sommerfeld, J. (2020). Land-based intervention: a qualitative study of the knowledge and practices associated with one approach to mental health in a Cree community. International Journal of Mental Health and Addiction, 18(1), 207-221.

Yang, T., \& Warburton, D. E. (2018). Indigenous elders' role in fostering intergenerational relationships with youth. The Health \& Fitness Journal of Canada, 11(4), 88-93.

\section{Appendix 1}

\section{Smart Indigenous Youth (SIY) Focus Group 2}

\section{Culture and identity}

The first few questions we'll discuss are about your culture and identity. Culture means where you're from, teachings from your family and community, and our history.

1a) What kind of cultural teachings/activities were part of your school program?

1b) What did you learn about your culture from the school program?

2) Has learning about your culture become more important to you after participating in this program?

3a) Do you feel a change in your cultural identity since starting the program?

3b) What did you learn about your cultural identity? Do you feel a stronger connection to your culture since starting the school program?

Transition (if possible). Otherwise note that we're moving to another topic area (i.e., now we'd like to talk about physical activity in your community). 


\section{Active Living}

4) What kind of activities did you learn and participate in?

5) What kind of cultural or traditional activities did you participate in as a result of this program?

6) Do you think the program helped you become more culturally involved?

Transition into next topic by noting that physical activity is known to affect your mental health and how you feel.

\section{Mental Health}

7) Do you feel that the program affected your mental health in any way?

Probe: Have there been any changes to your mental health as a result of participating in the program?

8) How do you feel about being in school as a result of this program? 